\title{
Scaling wood volume estimates from inventory plots to landscapes with airborne LiDAR in temperate deciduous forest
}

\author{
Shaun R. Levick ${ }^{1 *}$, Dominik Hessenmöller ${ }^{2}$ and E-Detlef Schulze ${ }^{1}$
}

\begin{abstract}
Background: Monitoring and managing carbon stocks in forested ecosystems requires accurate and repeatable quantification of the spatial distribution of wood volume at landscape to regional scales. Grid-based forest inventory networks have provided valuable records of forest structure and dynamics at individual plot scales, but in isolation they may not represent the carbon dynamics of heterogeneous landscapes encompassing diverse land-management strategies and site conditions. Airborne LiDAR has greatly enhanced forest structural characterisation and, in conjunction with field-based inventories, it provides avenues for monitoring carbon over broader spatial scales. Here we aim to enhance the integration of airborne LiDAR surveying with field-based inventories by exploring the effect of inventory plot size and number on the relationship between field-estimated and LiDAR-predicted wood volume in deciduous broad-leafed forest in central Germany.

Results: Estimation of wood volume from airborne LiDAR was most robust $\left(\mathrm{R}^{2}=0.92, \mathrm{RMSE}=50.57 \mathrm{~m}^{3}\right.$ $\left.\mathrm{ha}^{-1} \sim 14.13 \mathrm{MgCha}{ }^{-1}\right)$ when trained and tested with 1 ha experimental plot data $(\mathrm{n}=50)$. Predictions based on a more extensive $(n=1100)$ plot network with considerably smaller $\left(0.05\right.$ ha) plots were inferior $\left(R^{2}=0.68\right.$, RMSE $=101.01 \sim 28.09 \mathrm{Mg} \mathrm{C} \mathrm{ha}^{-1}$ ). Differences between the 1 and 0.05 ha volume models from LiDAR were negligible however at the scale of individual land-management units. Sample size permutation tests showed that increasing the number of inventory plots above 350 for the 0.05 ha plots returned no improvement in $R^{2}$ and RMSE variability of the LiDAR-predicted wood volume model.
\end{abstract}

Conclusions: Our results from this study confirm the utility of LiDAR for estimating wood volume in deciduous broad-leafed forest, but highlight the challenges associated with field plot size and number in establishing robust relationships between airborne LiDAR and field derived wood volume. We are moving into a forest management era where field-inventory and airborne LiDAR are inextricably linked, and we encourage field inventory campaigns to strive for increased plot size and give greater attention to precise stem geolocation for better integration with remote sensing strategies.

Keywords: Broad-leafed, Carbon, Forest, LiDAR, Inventory, Wood volume, Temperate

\section{Background}

Temperate forests have functioned as significant sinks of atmospheric carbon dioxide $\mathrm{CO}_{2}$ over the last few

\footnotetext{
${ }^{*}$ Correspondence: slevick@bgc-jena.mpg.de

1 Department of Biogeochemical Processes, Max Planck Institute for Biogeochemistry, Hans-Knoell-Str. 10, 07745 Jena, Germany Full list of author information is available at the end of the article
}

decades, but their capacity for continued carbon sequestration is uncertain $[1,2]$. Modelled estimates of the size and duration of the sink are highly variable, and reducing this uncertainty requires better quantification of how much carbon is stored in different forests types, how it is spatially distributed across environmental and land-management gradients, and how it changes over

\section{Springer Open}


time. This task becomes increasingly urgent in view of the Paris Protocol where national sinks will balance national emissions. Estimates of above ground carbon stock have traditionally been measured and monitored through field-based inventories on a grid-scale [3]. These approaches typically rely upon allometric equations to scale simple field measures of tree structure (diameter at breast height, height) to wood volume-and ultimately to carbon mass by accounting for wood density $[4,5]$. Allometric scaling has inherent limitations [6], but additional constraints of field-based inventories for regional scale analyses are the restricted spatial coverage of inventory plots, the time cost associated with conducting thorough wood volume estimations on the ground, and a lack of techniques to measure complete wood volume without the actual harvesting of stems.

Airborne light-detection and ranging (LiDAR) has emerged as a key remote sensing technology for advancing the mapping of forest structure and biomass over larger spatial scales [7-9]. The core strength of airborne LiDAR lies in its ability to accurately measure vegetation canopy height remotely, enabling detailed and georeferenced three-dimensional (3D) representations of canopy structure and associated biophysical parameters. Height and canopy density metrics derived from LiDAR have proven to be well correlated with above ground biomass (AGB) in a broad range of ecosystems-from semi-arid savannas to tropical forests [7, 10-13]. AGB mapping with airborne LiDAR is most commonly conducted by deriving empirical models between a suite of LiDAR metrics and field-measured AGB values obtained from georeferenced field sample plots. This relationship is then applied across the broader area of LiDAR data coverage at the same spatial resolution as the field sample plots from which the relationship was derived. As the number of studies comparing field-based estimates of AGB with LiDAR derived metrics has increased over the past decade, it has become increasingly apparent that performance is dependent upon the forest type and both the size and number of the field plots used for model development and evaluation [14-16]. Certain forest types lend themselves better to airborne characterization than others (e.g. conifers vs broad-leafed trees). Forests with relatively simple and regular structures, like those found in the boreal zone, are particularly well suited to characterization by airborne LiDAR [17-19]. Irrespective of forest type however, calibration errors between field measured and LiDAR predicted AGB tend to increase with decreasing plot size $[15,16]$. This pattern partly arises from increasing edge effects as plots get smaller. Smaller plots have a greater edge length to area ratio than larger plots, and errors arising from GPS position uncertainty are also more pronounced in smaller than larger plots, as the same positioning offset will cause greater misalignment between field and LiDAR data in smaller than larger plots. Lastly, temporal differences between field and LiDAR data acquisitions can also strain the relationship between field and LiDAR measured AGB-due to natural growth/mortality, harvest, land-use and land-use change [20].

Despite the limitation of smaller plot size discussed above, sample plots of approximately 0.05 ha in size (25 $\mathrm{m}$ diameter) are standard for national forest inventories across much of the temperate zone [21]. As the science of forest management and forest inventory moves into a new era with greater inclusion of remotely sensed data to support monitoring and decision-making, we need better understanding of how well current field inventory approaches represent key forest variables at landscape to regional scales.

In this study we aimed to: (i) compare relationships between airborne LiDAR and wood volume estimates obtained from small (0.05 ha) and large (1 ha) field inventory plots; (ii) scale wood volume estimates from small (0.05 ha) and large ( $1 \mathrm{ha})$ inventory plots to the spatial extent of regional land-management units with airborne LiDAR; (iii) examine the consequence of using small $(0.05 \mathrm{ha})$ or large ( $1 \mathrm{ha})$ field inventory plots for training airborne LiDAR extrapolations at the scale of land-management units; and (iv) determine the number of plots needed to adequately train LiDAR based extrapolations at landscape to regional scales.

\section{Methods}

Study site

This study was conducted in the Hainich-Dün region of Thuringia, Germany $\left(51^{\circ} 12^{\circ} \mathrm{N} 10^{\circ} 18^{\circ} \mathrm{E}\right)$. Elevation ranges from 100 to $494 \mathrm{~m}$ above sea level and the region experiences a mean annual precipitation of $600-800 \mathrm{~mm}$ and a mean annual temperature of $6-7.5{ }^{\circ} \mathrm{C}$. The parent material is limestone, which is covered in places by a loess layer of variable thickness (ca. 10-50 cm). Primary soil groups of the study area are Cambisols, Luvisols and Stagnosols [22]. The climate and soil conditions of the region provide optimum growing conditions for beech (Fagus sylvatica L.) dominated forests, with admixtures of Fraxinus excelsior L., Acer pseudoplatanus L. and Acer platanoides $\mathrm{L}$.

At the turn of the 19th century, most of the forest sites in the Hainich-Dün region were under the coppice-withstandards system-a silvicultural system in which timber trees with an open canopy are grown above a coppiced woodland [23]. Small areas of selectively cut forests were also present, with selective harvesting of single trees and irregular forest use. In the early 19th century, all coppicewith-standards forests were converted to age-class forest 
or to selectively cut forest [24]. The forest under age-class management is characterised by a sequence of relatively homogenous, even-aged stands. Coppice-with-standards management is no longer practiced in the Hainich-Dün region.

\section{Field-inventory plot measurements}

We used two different sets of existing field plots for comparison and extrapolation with airborne LiDAR data. The first set consisted of 50 large 1 ha plots $(100 \times 100 \mathrm{~m})$ that were established as part of the Biodiversity Exploratories programme (see [25] for more details) to cover different forest and management types of deciduous forest within the region. The second set is a subset of the existing regional grid based forest inventory, totalling 1100 circular plots of $25 \mathrm{~m}$ diameter (0.05 ha) [26].

A comprehensive forest inventory was conducted in each of the 1 ha plots-with the species, height and stem diameter at breast height (DBH) recorded for all of trees with a DBH of $>7 \mathrm{~cm}$. In the 0.05 ha plots, a typical fixed area plot approach was used whereby: (i) all stems with $\mathrm{DBH}<=7 \mathrm{~cm}$ were measured within a $5 \mathrm{~m}$ radius of the plot centre point; (ii) stems with a DBH $<12 \mathrm{~cm}$ were recorded within a $7 \mathrm{~m}$ of the plot centre point; (iii) stems with a DBH $>12 \mathrm{~cm}$ were measured within a $12.5 \mathrm{~m}$ radius of the plot centre point. Thus, each inventory point yields information about stand density and diameter distribution when expanding to a common area. The conversion into wood volume follows allometric relationships, which include the form and taper of tree stems [5].

\section{Airborne LiDAR surveying}

Airborne LiDAR surveying was conducted by Milan $\mathrm{GmbH}$ in August 2008 during leaf-on conditions. A Riegl LMS-Q560 full-wave form scanner (Riegl Laser Measurement Systems, GmbH, Horn, Austria) was operated at $240 \mathrm{kHz}$ from $400-600 \mathrm{~m}$ above ground level. Beam divergence was $0.5 \mathrm{mrad}$ and footprint size varied from 20-30 cm. An average pulse density of 16 per $\mathrm{m}^{2}$ and a mean point spacing of $0.24 \mathrm{~m}$ was achieved across the study site, providing excellent representation of the three-dimensional structure of canopy over $100 \mathrm{~km}^{2}$ of forest (Fig. 1).

\section{Airborne LiDAR processing}

The geolocated LiDAR point clouds were projected into the UTM $32 \mathrm{~N}$ reference system and classified into ground and vegetation returns using the LAStools suite of processing tools (rapidlasso $\mathrm{GmbH}$ ). A high-resolution digital terrain model (DTM) was interpolated from the ground-classified points at $1 \mathrm{~m}$ spatial resolution using a triangulated network (TIN) approach. The DTM was used to normalize the LiDAR point clouds to height above ground level. Field inventory plot centre locations were imported into the same projection system and buffered to create $25 \mathrm{~m}$ diameter circular polygons and $100 \mathrm{~m}$ wide square polygons centred on their respective inventory centre points. These polygons were used to clip and export the normalized LiDAR points falling inside each of the field inventory plots. The exported plot LiDAR points were then analysed in FUSION/LDV [27] to derive the suite of 25 structural metrics listed in Table 1, using a height threshold of $0.5 \mathrm{~m}$ above ground level to define vegetation returns.

\section{Establishing relationships between airborne LiDAR metrics and field-measured wood volume}

We used two approaches to establish relationships between metrics derived from airborne LiDAR surveying and field-measured wood volume for both the 0.05 ha and 1 ha datasets. In the first approach we conducted step-wise linear regression with AIC minimisation to identify the LiDAR derived variables with the most explanatory power. In the second approach we employed machine learning using the Random Forest Algorithm on the same suite of variables and compared these results to those obtained from the simpler step-wise linear regression approach. In both cases we randomly selected $70 \%$ of the data for training and used the remaining $30 \%$ for cross validation.

\section{Exploring the consequence of using small or large field inventory plots for training airborne LiDAR extrapolations at the scale of land-management units}

We used the best model (in terms of explanatory power and RMSE) for each plot size to extrapolate wood volume across the full extent of the available LiDAR coverage. We then intersected these regional wood volume maps with forest management GIS layers and compared the correlation between the extrapolated model derived from 0.05 ha plots and that derived from 1 ha plots on a land management unit basis.

\section{Establishing the influence of inventory plot sample size on wood volume relationships with airborne LiDAR}

The number of inventory plots used in our study is considerably larger than most other studies linking airborne LiDAR to field estimates. In order to understand how increasing sample size influences the resulting relationship between field and airborne estimates, we developed a permutation simulation test in $\mathrm{R}$ to explore the effects of sample size on the correlation between the LiDAR metric with the most explanatory power and field-measured wood volume. Our approach involved: (i) the random selection of $x$ plots from the full field dataset; (ii) fitting a linear regression between wood 


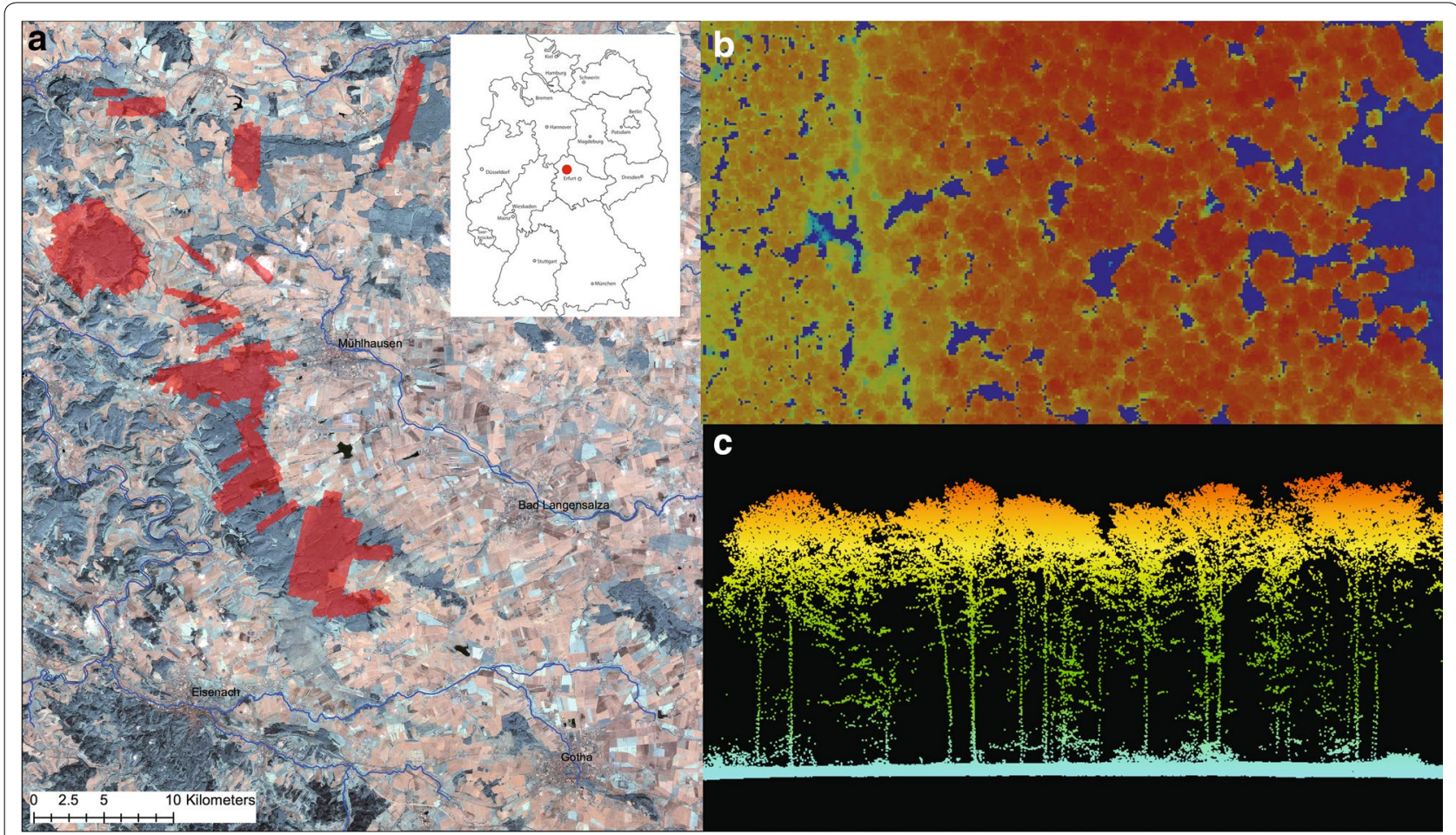

Fig. 1 Aerial overview of study region in central Germany with LiDAR survey areas shown in red (a). Large overlap between flight lines and low flying altitude enabled high-resolution characterisation of forest canopy structure in both rasterised (b) and 3D point cloud (c) space

volume and LiDAR metric; (iii) repeating steps i and ii $y$ times and quantifying the distribution of the regression outputs. For the 0.05 ha dataset, $x$ ranged from 25-1000 in increments of 25 plots. For the 1 ha dataset, $x$ ranged from $5-50$ in increments of five plots. We ran 1000 permutations $(y)$ for each sample size step in both datasets, resulting in a total of 40,000 linear regressions for the 0.05 ha dataset, and 10,000 linear regressions for the 1 ha dataset. We plotted box-plots of the $\mathrm{R}^{2}$ and the RMSE of from the linear regression outputs at each sample size step.

\section{Results}

\section{Relationship between airborne LiDAR and field-measured} wood volume

LiDAR derived mean canopy height $(\mathrm{MCH})$ was well correlated with field-estimated wood volume at both the 1 ha and 0.05 ha scales (Fig. 2a, b). Step-wise multiple linear regression analysis showed that a combination of LiDAR derived height metrics could account for $92 \%$ of the variation in field-measured wood volume at the 1 ha plot scale $\left(R^{2}=0.92\right.$, RMSE $=50.79$, Fig. 3a). Five explanatory variables were retained in the final model (determined by AIC minimisation)-variance of canopy height (var), the 20th, 40th, and 70th percentiles ( $q 2, q 4$, q7) and kurtosis (kur). The 70th percentile height (q7) was the most important explanatory variable, but inclusion of the other metrics reduced the RMSE.

$$
\begin{aligned}
\text { Wood volume }(1 \mathrm{ha})= & 120.32+-1.74(\text { var })+-4.38(q 2) \\
& +16.64(q 4)+9.7(q 7)+-11.05(\text { kur })
\end{aligned}
$$

The same analysis for the 0.05 ha plots showed that LiDAR derived metrics could only account for $68 \%$ of the variation in wood volume at this scale $\left(R^{2}=0.68\right.$, RMSE $=101.01$, Fig. 3b). Mean canopy height was the most important explanatory variable, but $\mathrm{CV}$ was also significant and its inclusion reduced the RMSE.

$$
\begin{aligned}
\text { Wood volume }(0.05 \mathrm{ha})= & -144.85+25.89(\mathrm{MCH}) \\
& +67.64(\mathrm{CV})
\end{aligned}
$$

There was a lot more scatter in the 0.05 ha relationships, and the RMSE was almost double that of the 1 ha scale plots. Evaluation of the model residuals showed no spatial pattern and there was no trend with increasing terrain slope (Fig. 4).

Random Forest modelling produced the same results and explanatory variables as the step-wise linear regressions, with only marginal improvements in RMSE. As such we used the simpler multiple linear regression equations for our landscape extrapolations. 
Table 1 List of canopy structural metrics derived from airborne LiDAR

\begin{tabular}{|c|c|}
\hline Canopy structural metric & Abbreviations \\
\hline Total number of returns & totRET \\
\hline Count of returns by return number & $\begin{array}{l}\text { ret1, ret2, ret3, ret4, ret5, ret6, ret7, } \\
\text { ret8, ret9 }\end{array}$ \\
\hline Minimum & $\operatorname{minCH}$ \\
\hline Maximum & $\operatorname{maxCH}$ \\
\hline Mean & $\mathrm{MCH}$ \\
\hline Median & medCH \\
\hline Mode & $\operatorname{modCH}$ \\
\hline Standard deviation & stdev \\
\hline Variance & var \\
\hline Coefficient of variation & $\mathrm{CV}$ \\
\hline Interquartile distance & intD \\
\hline Skewness & skew \\
\hline Kurtosis & kurt \\
\hline Average absolute deviation & $A A D$ \\
\hline $\begin{array}{l}\text { Median of the deviations from the } \\
\text { overall median }\end{array}$ & MADmed \\
\hline $\begin{array}{l}\text { Median of the deviations from the } \\
\text { overall mode }\end{array}$ & MADmod \\
\hline L-moments (L1, L2, L3, L4) & $\mathrm{L} 1, \mathrm{~L} 2, \mathrm{~L} 3, \mathrm{~L} 4$ \\
\hline L-moment skewness & Lskew \\
\hline L-moment kurtosis & Kurt \\
\hline Percentile values (5th-95th) & $\begin{array}{c}q 1, q 5, q 10, q 20, q 25, q 30, q 40, q 50, \\
q 60, q 70, q 75, q 80, q 90, q 95, q 99\end{array}$ \\
\hline Canopy relief ratio & CRR \\
\hline Quadratic mean & CQM \\
\hline Cubic mean & CCM \\
\hline Canopy cover & cov \\
\hline Canopy density & dens \\
\hline Strata counts & $\begin{array}{l}s 2, s 4, s 6, s 8, s 10, s 12, s 14, s 16, s 18 \\
s 20, s 22, s 24, s 26, s 28, s 30, s 32 \\
s 34, s 36, s 38, s 40\end{array}$ \\
\hline
\end{tabular}

\section{Extrapolating wood volume to landscape scale management units with airborne LiDAR}

Extrapolation of wood volume from inventory plots to landscape scales with airborne LiDAR revealed a high degree of spatial variability in wood volume distribution, with the influence of forest management clearly evident in the patch characteristics (Fig. 5). The extrapolation from the 1 ha plots (Fig. 5a) produced a smoother distribution of wood volume with lower variance, as expected, whilst the 0.05 ha plot extrapolation retained higher spatial detail with greater variance (Fig. 5b). At the scale of individual forest management units, however, these differences are largely averaged out with strong linear correlation between LiDAR derived wood volume estimates from 1 and 0.05 ha models (Fig. 6).
The influence of inventory plot sample size on wood volume relationships with airborne LiDAR

The median $R^{2}$ value of the fit between field and LiDAR estimated wood volume at the 0.05 ha scale remained constant as the number of plots increased from 25 to 1000 (Fig. 7a). The variation around the median values decreased with increasing number of plots. With the smallest number of plots $(n=25)$ the range in $R^{2}$ values spanned $0.37-0.91$, and stability was only achieved with greater than 350 inventory plots. The same patterns held true for the RMSE, whereby the median values were consistent with increasing number of plots, but stability in the range between high and low values was achieved with plot numbers greater than 350 (Fig. 7b).

The pattern of decreasing range in $\mathrm{R}^{2}$ and RMSE values with increasing number of plots was repeated at the 1 ha scale (Fig. 8a, b). Median values where consistent at sample size of greater than 10 plots of 1 ha, and stability in the range between high and low values was achieved when the number of inventory plots was greater than 30 .

\section{Discussion}

Airborne LiDAR provides direct measurement of forest canopy height, but no information on $\mathrm{DBH}$, which is the most commonly used (and often the sole) correlate of wood volume in field inventories. Establishing consistent and transferable relationships between wood volume and canopy structural variables that airborne LiDAR can acquire is important for enhancing forest inventory and long-term monitoring of aboveground biomass over large spatial areas. Our results from this study in central Germany confirm the utility of LiDAR for estimating wood volume in deciduous broad-leafed forest, but highlight the challenges of field plot size and number in establishing robust relationships between airborne LiDAR and field inventory derived wood volume.

Estimation of wood volume from airborne LiDAR was most robust $\left(\mathrm{R}^{2}=0.92\right.$, RMSE $\left.=50.79 \mathrm{~m}^{3} \mathrm{ha}^{-1}\right)$ when trained and tested with the 1 ha experimental plot data. Predictions based on the more extensive but considerably smaller $(0.05 \mathrm{ha})$ inventory plots were inferior $\left(R^{2}=0.68\right.$, RMSE $=101.01 \mathrm{~m}^{3} \mathrm{ha}^{-1}$ ). In above ground carbon terms, assuming a mean wood density of $0.57 \mathrm{~g} \mathrm{~cm}^{-3}$ [28] and a carbon content of 0.488 for temperate broad-leafed species [29], these findings relate to RMSE values of 14.13 $\mathrm{Mg} \mathrm{C} \mathrm{ha}^{-1}$ for the 1 ha plots and $28.09 \mathrm{Mg} \mathrm{C} \mathrm{ha}^{-1}$ for the 0.05 ha plots. Higher error in the smaller plots was not unexpected, as larger plot sizes smooth out much of the variability inherent at smaller scales, e.g. the shelter wood harvest is only visible based on 0.05 ha resolution (Fig. 5). What was surprising however was the lack of any spatial pattern in the residuals of the fit between 

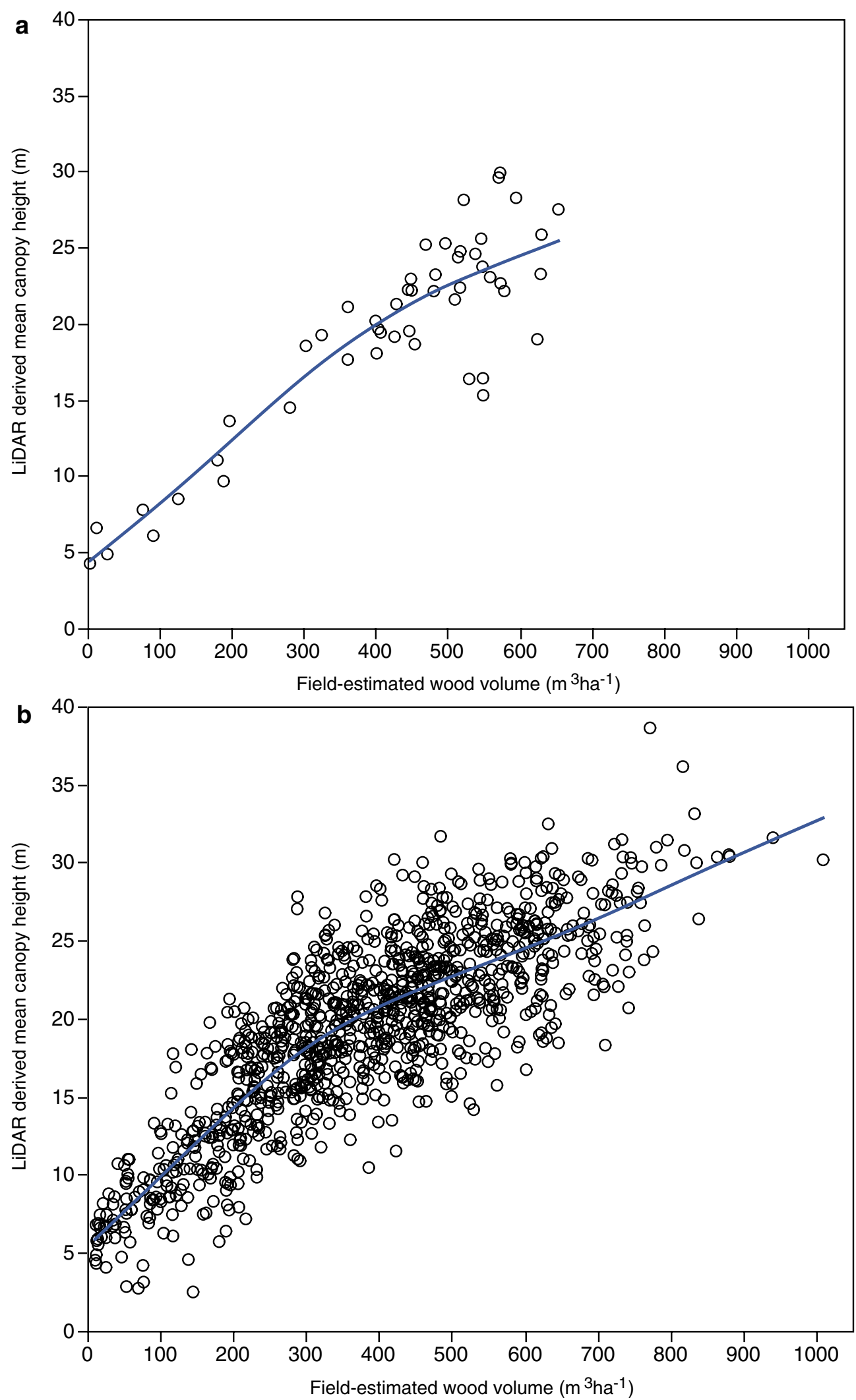

Fig. 2 Relationship between field-estimated wood volume and LiDAR derived mean canopy height (MCH) at 1 ha (a) and 0.05 ha (b) plot scales 

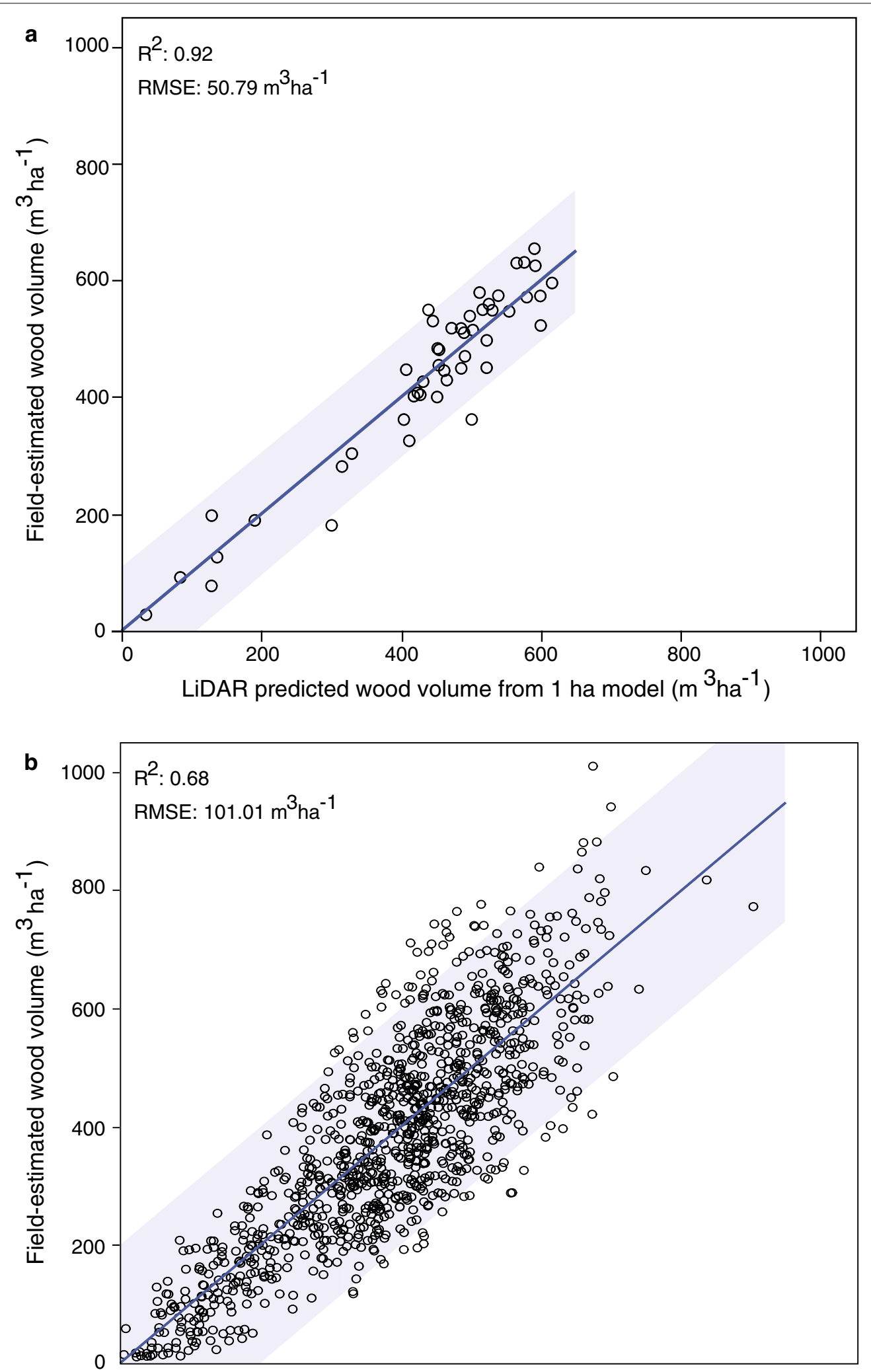

Fig. 3 Validation of LiDAR-predicted wood volume against field-estimated wood volume at 1 ha (a) and 0.05 ha (b) plot scales 


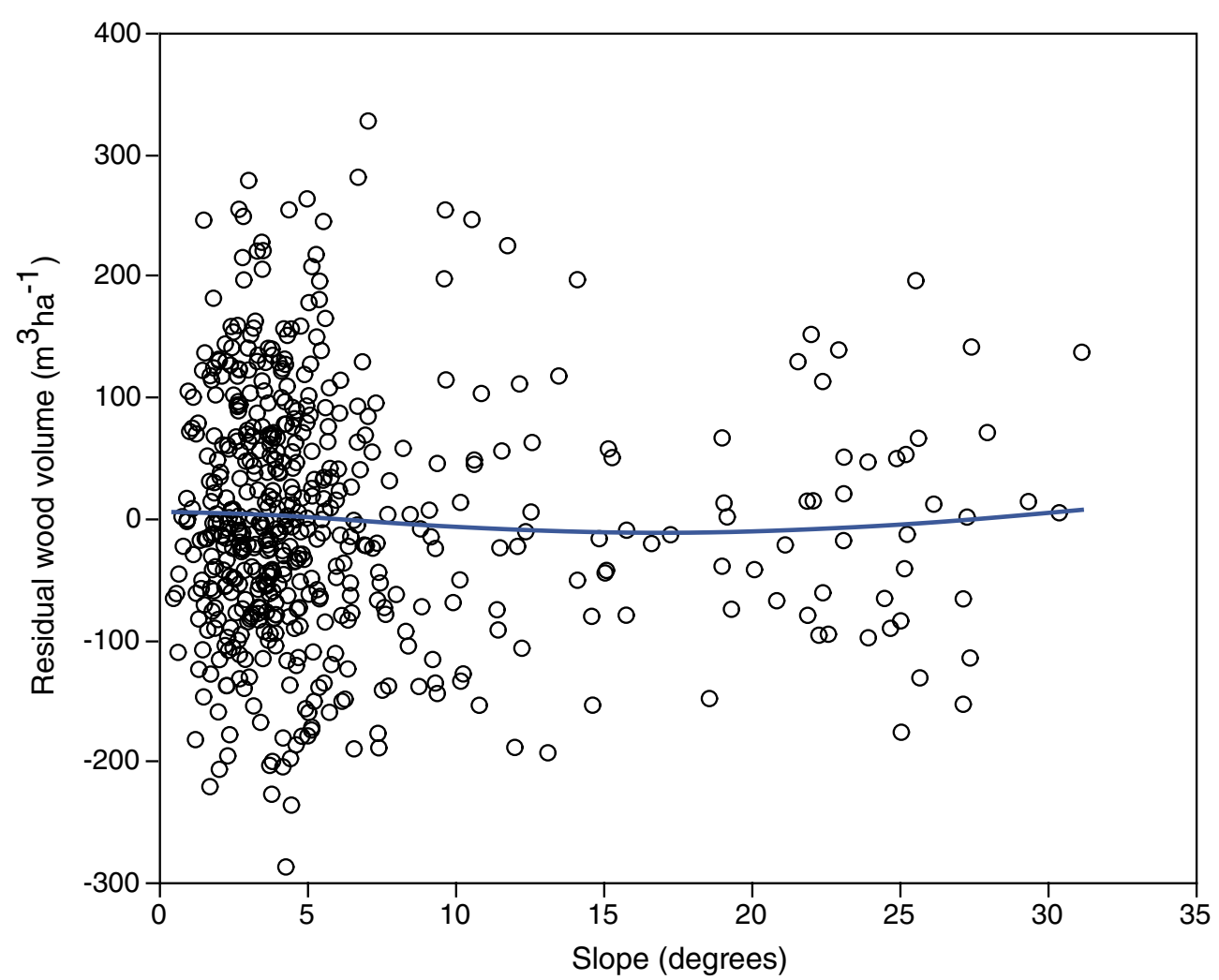

Fig. 4 Pattern of LiDAR-predicted versus field-estimated wood volume model residuals ( 0.05 ha plots) in relation to terrain slope

field-measured and LiDAR-predicted wood volume. We anticipated that plots situated on steeper slopes would deviate more from LiDAR-predicted values than those on flatter slopes due to variations in growth patterns, variations in canopy architecture and the increased difficulty of collecting geolocated field data in steep environments. This was not the case however as we found no spatial trends in the residuals and there was no significant relationships between slope attributes and the model residuals (Fig. 4). Furthermore, the even distribution of residuals above and below zero indicates equal probability of over- and under-estimation of wood volume from the 0.05 ha LiDAR model, suggesting a more random source of error.

Given the lack of environmental variation in the 0.05 ha model residuals and their uniform distribution, we consider edge effects to be the most likely cause of LiDAR prediction errors. Edge effects become more pronounced when plot size decreases, as greater proportions of tree canopy bisect the plot boundary [30]. During field inventory, trees rooted just inside the plot boundary contribute their full wood volume to the total plot estimate-yet any canopy extending over the boundary is ignored in the LiDAR analysis which clips the point cloud with the exact boundary dimensions of the field plot. This scenario would lead to an underestimation of plot wood volume from LiDAR. Similarly, any tree rooted just outside of a plot would not be recorded in the field wood volume inventory, but any of its branches and canopy that extend into the plot are included in the LiDAR analysis-leading to possible overestimations of plot wood volume from LiDAR. As such, these edge effects present equal opportunity for over- or under-estimations to arise, depending on the tree trunk geographic location in relation to the plot boundary line. These edge effect artefacts could be avoided, or at least minimised, by adopting a "crowndistributed" carbon density approach in the LiDAR analysis stage. Typical field inventories place carbon in space according to the geographic location of each stem ("stem-localised" approach), but as Mascaro et al. [15] and Packalen et al. [30] have shown, its makes more sense to distribute carbon spatially according to the foot-print of the tree's crown ("crown-distributed" approach). The crown-distributed carbon density approach is more suitable for LiDAR-based investigations as LiDAR energy is returned more strongly by leaves and branches orientated perpendicular to the sensor, than stem boles orientated directly towards the sensor [15].

Successfully implementing a crown-distributed carbon density approach, however, relies on the delineation 


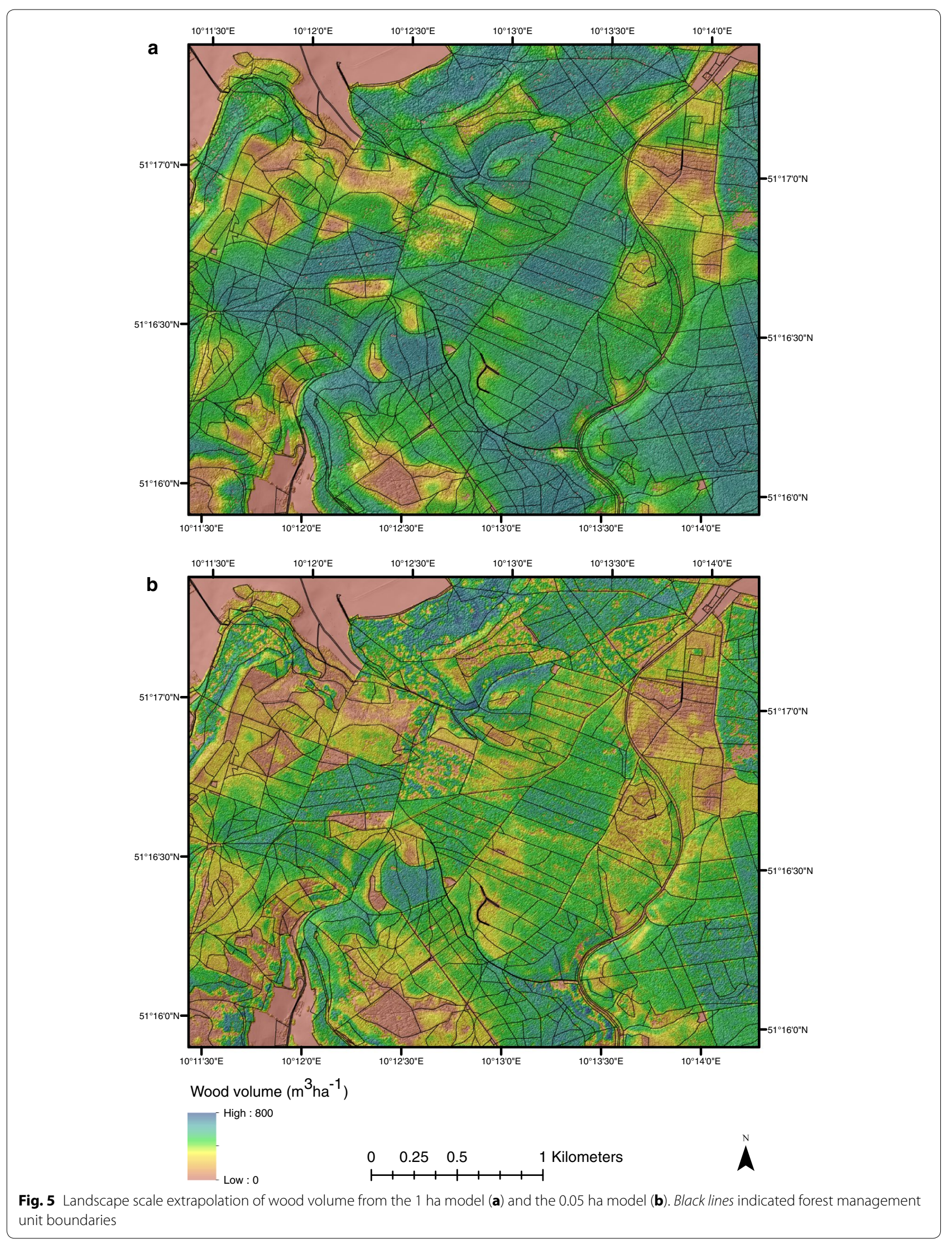




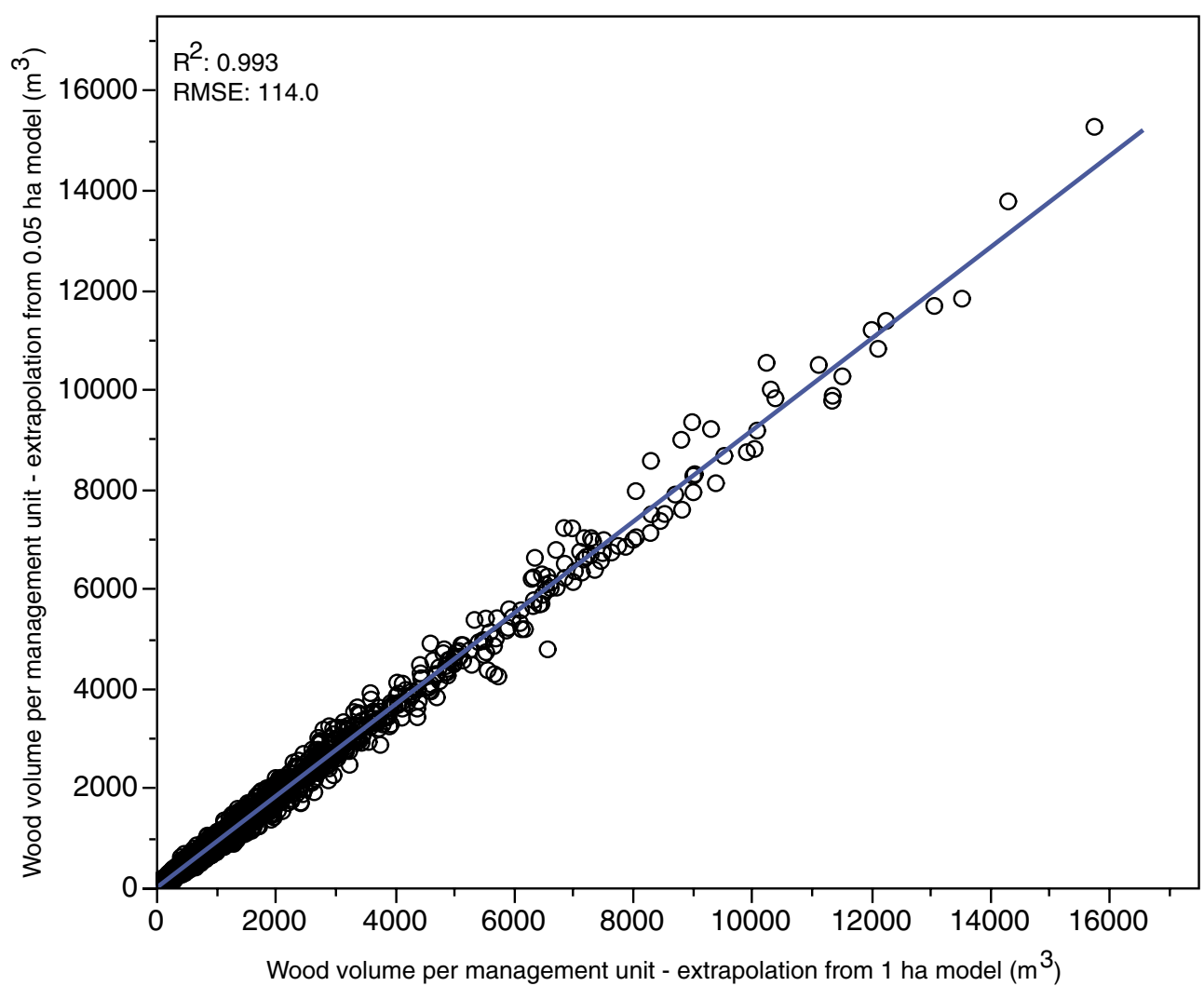

Fig. 6 Relationship between total wood volume predictions from the 1 and 0.05 ha models on a per management unit basis

and identification of individual trees crowns in the airborne LiDAR data. Although much progress has been made in this direction through top-down segmentation of normalised canopy models [31-33], individual tree detection success is heavily dependant upon forest type. High accuracies have been recorded in coniferous forest and savanna, but success of individual crown delineation decreases as the complexity of canopy structure increases, and the interlocking crowns of broad-leafed temperate forest render them particularly challenging for automated individual crown separation [34-36]. Recent advances in bottom-up region growing techniques that identify trunk locations and segment their connected crowns within the LiDAR point cloud [35, 37] could prove useful in these forests. Airborne LiDAR datasets with higher pulse densities, preferably collected in leafoff conditions, would be needed however to achieve sufficient returns from tree trunks to enable bottom-up delineation.

Despite the differences observed in the relationship between field-estimated and LiDAR-predicted wood volume at 1 and 0.05 ha plot scales, and the possible improvements that could be made in future LiDAR analyses, the greater uncertainty in the 0.05 ha model was of minimal consequence when scaling wood volume to land-management units across the entire landscape. We found hardly any difference between total wood volume estimates derived from the 1 and 0.05 ha models for individual landmanagement units $\left(R^{2}=0.99\right.$, RMSE $\left.=114 \mathrm{~m}^{3}\right)$. Nonetheless, reducing unexplained variation in the 0.05 ha model is important for ecological questions or management decisions operating at smaller scales, and for evaluating canopy dynamics over time. Although our results show minimal difference between 1 and 0.05 ha models at the scale of land-management units, we need greater exploration of how a broader range of plot sizes impact scaling relationships, across different forest types, to optimise the integration of field-based and airborne inventories.

In addition to advancing the LiDAR processing chain by adopting individual tree and crown-distributed carbon density approaches, uncertainty could be further reduced through improvements the field-inventory data collection. Common forest inventory systems in much of Europe utilise a fixed area sampling approach of three concentric circles of increasing distance from plot centre $(5,7,12.5 \mathrm{~m})$ and trees are sub-sampled according to DBH thresholds [38]. This approach assumes homogenous distribution of size classes across the plot, 

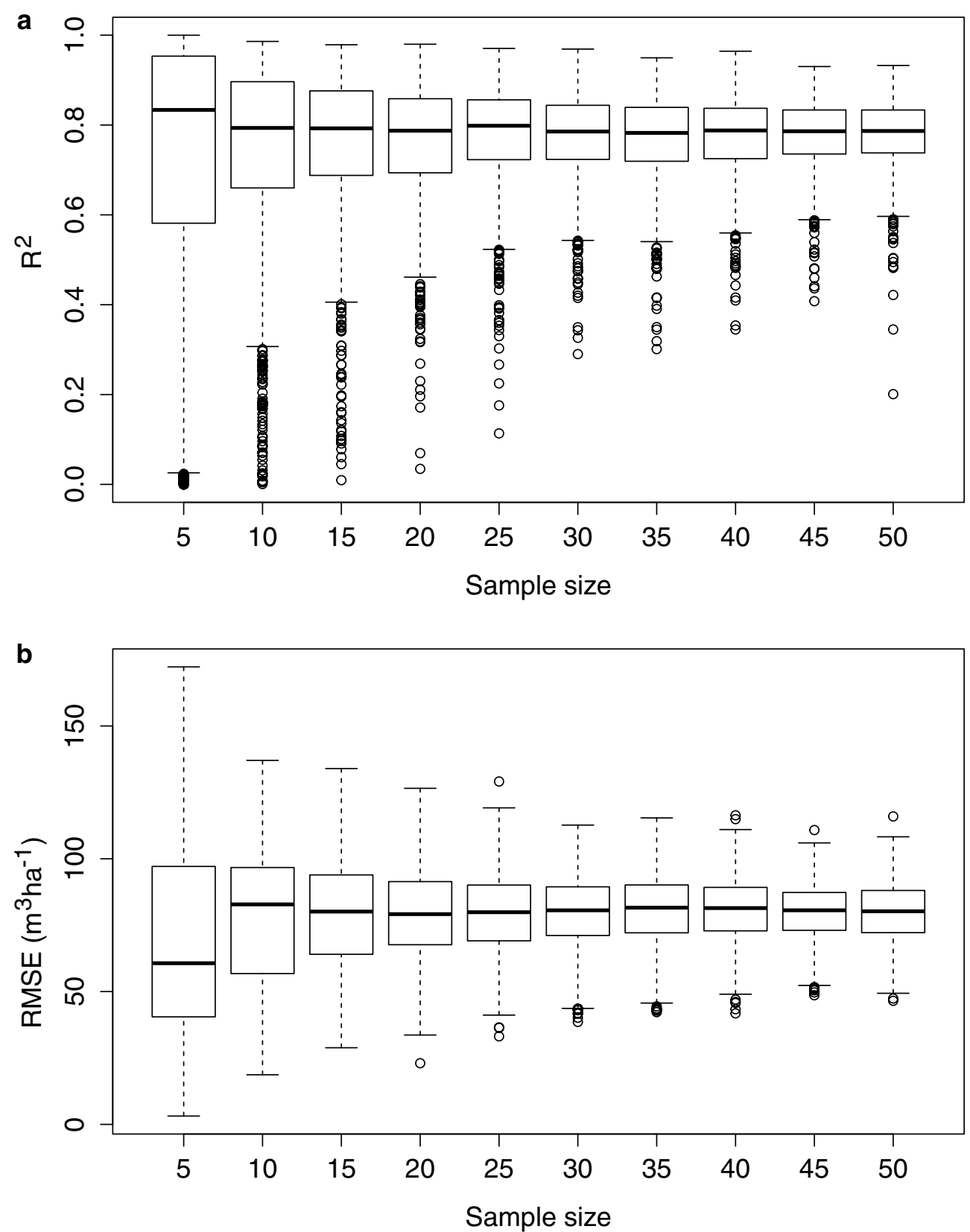

Fig. 7 The influence of sample size (number of plots) on the proportion of variation in wood volume explained by LiDAR metrics—coefficient of determination (a) and root mean square error $(\mathbf{b})$ - at the 1 ha plot scale

which is unlikely to hold true in reality. Measurement of all trees within the plot area would avoid this source of uncertainty, but involves greater time costs, and it would not significantly change the total volume estimate which depends on the coverage of the dominant trees. Nested fixed-area sampling approaches for forest inventory were developed to reduce sampling time per plot, and enable a higher number of plots to be sampled over more land area [39]. Our permutation tests in this study show however that very large plot numbers may yield limited benefit. Indeed, in terms of establishing relationships between field-estimated wood volume and airborne LiDAR metrics, increasing the number of plots beyond 350 does not improve the range of attained $\mathrm{R}^{2}$ and RMSE values (Fig. 6). In situations were fieldinventory can be coupled with airborne LiDAR surveys, 

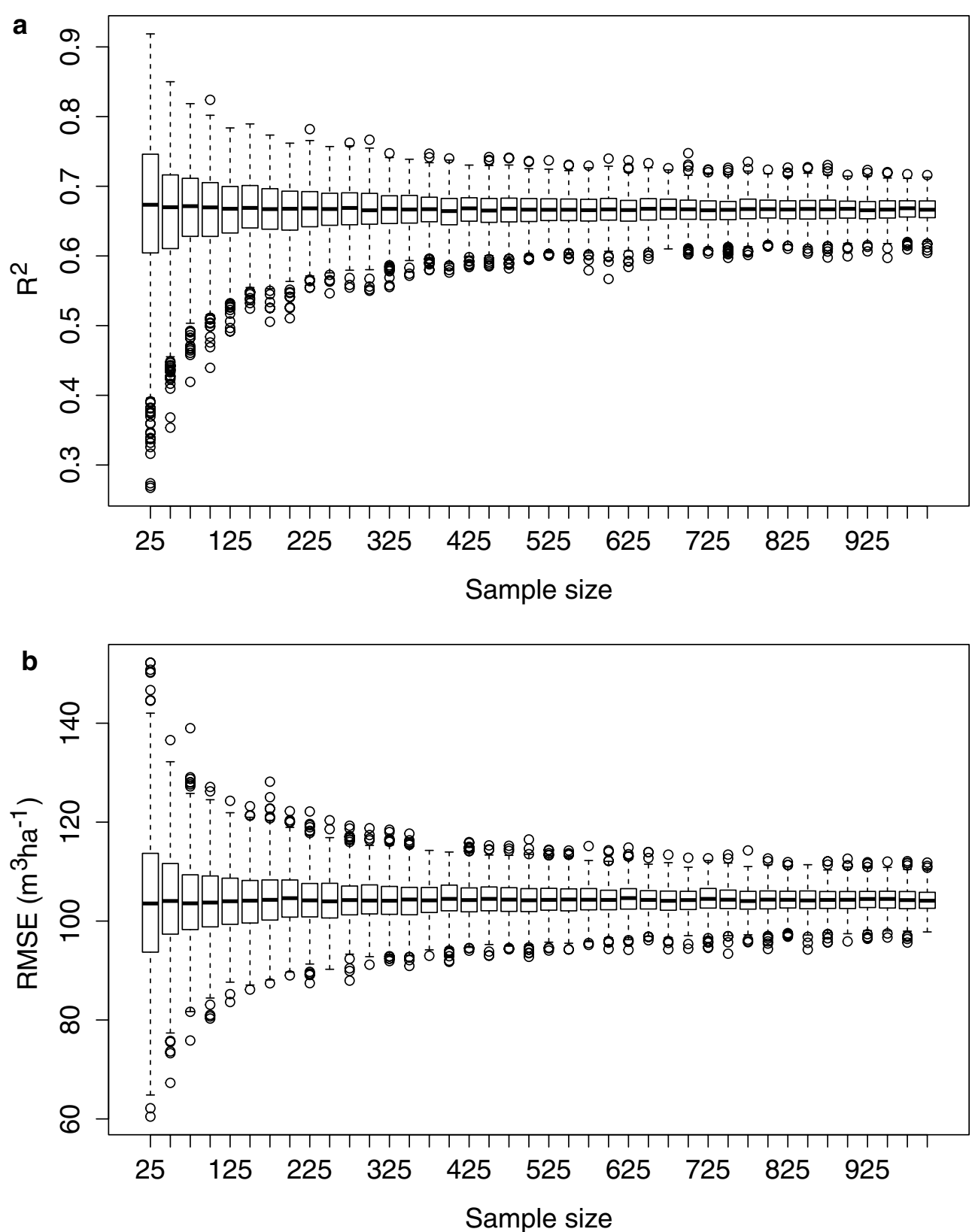

Fig. 8 The influence of sample size (number of plots) on the proportion of variation in wood volume explained by LiDAR metrics—coefficient of determination (a) and root mean square error (b) - at the 0.05 ha plot scale

it would therefore make more sense to spend time and effort on increasing field plot size, and ensuring measurement of all stems, than increasing number alone. Moreover, the inclusion of airborne LiDAR into forest management and monitoring strategies can improve the effectiveness of field-based inventories by informing plot stratification over heterogeneous landscapes [12, $17,40]$. Lastly, inclusion of recent advances in terrestrial
LiDAR sampling [41-43] into the field-inventory process would help reduce uncertainty of wood volume estimates at the plot scale, and facilitate integration of field and airborne data. Reducing uncertainty in the field to airborne scaling will be critical for validating upcoming global efforts to monitoring carbon stocks with spaceborne LiDAR, such as the global ecosystem dynamics investigation (GEDI) [44]. 


\section{Conclusions}

The results from our study in broad-leafed deciduous forest show that airborne LiDAR can be used very effectively to map wood volume in deciduous forest stands, and therefore quantify carbon stocks across large landscapes at high spatial resolutions. We suggest that field inventory campaigns should prioritise plot size and place greater emphasis on precise stem and crown geolocation for better integration with high-resolution remote sensing techniques. Ensuring accurate geolocation of individual stems provides greater flexibility in the analysis stages of fusing LiDAR with field data, by enabling sub-sampling to provide information at a greater range of scales. We are moving into a forest management era where field-inventory and airborne LiDAR are inextricably linked. Forest inventory campaigns and airborne LiDAR surveying should not operate independently, as each add considerable value to the other.

\section{Abbreviations}

DBH: diameter at breast height; LiDAR: light detection and ranging; RMSE: root mean square error; $\mathrm{MCH}$ : mean canopy height.

\section{Authors' contributions}

SRL and EDS designed the study. SRL processed and analyzed the LiDAR data, performed the analyses and wrote the paper. DH and EDS analyzed the field data and contributed to the writing of the paper. All authors read and approved the final manuscript.

\section{Author details}

1 Department of Biogeochemical Processes, Max Planck Institute for Biogeochemistry, Hans-Knoell-Str. 10, 07745 Jena, Germany. ${ }^{2}$ ThüringenForst AÖR, State Forest Service, P.O. Box 900105, 99104 Erfurt, Germany.

\section{Acknowledgements}

The Max Planck Institiute for Biogeochemistry provided funding for the airborne LiDAR surveying. We thank Jens Nieschulze for his involvement in coordinating the airborne LiDAR surveying, and Uli Pruschitzki and Claudia Seilwinder for their efforts in the field. We thank Carlos Sierra for his help designing the sample size permutation experiment in R, and Mikhail Urbasev for assistance with the RandomForest model. Comments from Olivier Bouriaud helped improve this manuscript.

\section{Competing interests}

The authors declare that they have no competing interests.

Received: 5 February 2016 Accepted: 14 May 2016

Published online: 31 May 2016

\section{References}

1. Pan Y, Birdsey RA, Fang J, Houghton R, Kauppi PE. A large and persistent carbon sink in the world's forests. Science. 2011;333:988-93.

2. Millar Cl, Stephenson NL. Temperate forest health in an era of emerging megadisturbance. Science. 2015;349:823-6.

3. Joosten R, Schumacher J, Wirth C, Schulte A. Evaluating tree carbon predictions for beech (Fagus sylvatica L.) in western Germany. For Ecol Manag. 2004;189:87-96.

4. Wirth C, Schumacher J, Schulze ED. Generic biomass functions for Norway spruce in Central Europe-a meta-analysis approach toward prediction and uncertainty estimation. Tree Physiol. 2004;24:121-39.
5. Wutzler T, Wirth C, Schumacher J. Generic biomass functions for common beech (Fagus sylvatica) in Central Europe: predictions and components of uncertainty. Can J For Res. 2008;38:1661-75.

6. Duncanson L, Rourke O, Dubayah R. Small sample sizes yield biased allometric equations in temperate forests. Sci Rep. 2015;5:17153.

7. Lefsky MA, Cohen WB, Harding DJ, Parker GG, Acker SA, Gower ST. LiDAR remote sensing of above-ground biomass in three biomes. Glob Ecol Biogeogr. 2002;11:393-9.

8. Asner GP, Mascaro J, Muller-Landau HC, Vieilledent G, Vaudry R, Rasamoelina M, Hall JS, Breugel M. A universal airborne LiDAR approach for tropical forest carbon mapping. Oecologia. 2011;168:1147-60.

9. Johnson KD, Birdsey R, Finley AO, Swantaran A, Dubayah R, Wayson C, Riemann R. Integrating forest inventory and analysis data into a LiDAR-based carbon monitoring system. Carbon Balance Manag. 2014;9:3.

10. Colgan MS, Asner GP, Levick SR, Martin RE, Chadwick OA. Topo-edaphic controls over woody plant biomass in South African savannas. Biogeosciences. 2012;9:1809-21.

11. Næsset E, Gobakken T. Estimation of above- and below-ground biomass across regions of the boreal forest zone using airborne laser. Remote Sens Environ. 2008:112:3079-90.

12. Wulder MA, White JC, Nelson RF, Næsset E, Ørka HO, Coops NC, Hilker T, Bater CW, Gobakken T. LiDAR sampling for large-area forest characterization: a review. Remote Sens Environ. 2012;121:196-209.

13. Popescu SC, Wynne RH, Scrivani JA. Fusion of small-footprint LiDAR and multispectral data to estimate plot-level volume and biomass in deciduous and pine forests in Virginia,USA. For Sci. 2004;50:551-65.

14. Næsset E. Estimating timber volume of forest stands using airborne laser scanner data. Remote Sens Environ. 1997;61:246-53.

15. Mascaro J, Detto M, Asner GP, Muller-Landau HC. Evaluating uncertainty in mapping forest carbon with airborne LiDAR. Remote Sens Environ. 2011;115:3770-4.

16. Strunk J, Temesgen $H$, Andersen $H-E$, Flewelling JP, Madsen L. Effects of LiDAR pulse density and sample size on a model-assisted approach to estimate forest inventory variables. Can J Remote Sens. 2014;38:644-54.

17. Næsset E. Practical large-scale forest stand inventory using a small-footprint airborne scanning laser. Scand J For Res. 2004;19:164-79.

18. Morsdorf F, Meier E, Kötz B, Itten Kl, Dobbertin M, Allgöwer B. LiDAR-based geometric reconstruction of boreal type forest stands at single tree level for forest and wildland fire management. Remote Sens Environ. 2004;92:353-62.

19. Holmgren J. Prediction of tree height, basal area and stem volume in forest stands using airborne laser scanning. Scand J For Res. 2004;19:543-53.

20. Levick SR, Setterfield S, Rossiter-Rachor N, Hutley L, MacMaster D, Hacker J. Monitoring the Distribution and dynamics of an invasive grass in tropical savanna using airborne LiDAR. Remote Sens. 2015;7:5117-32.

21. McRoberts RE, Tomppo EO, Næsset E. Advances and emerging issues in national forest inventories. Scand J For Res. 2010;25:368-81.

22. Grüneberg E, Schöning I, Kalko EKV, Weisser WW. Regional organic carbon stock variability: a comparison between depth increments and soil horizons. Geoderma. 2010;155:426-33.

23. Schulze ED, Hessenmöller D, Seele C, Wäldchen J, von Lüpke N. Die Buche. Eine Kultur- und Wirtschaftsgeschichte. Biol unserer Zeit. 2010;40:171-83.

24. Wäldchen J, Schulze ED, Mund M, Winkler B. Überblick über die Forstwirtschaft im Hainich-Dün Gebiet (Nordthüringen) im 19. Jahrhundert im Zusammenhang mit der politischen und wirtschaftlichen Entwicklung. Forstarchiv. 2011:82:35-47.

25. Fischer M, Bossdorf O, Gockel S, Hänsel F. Implementing large-scale and long-term functional biodiversity research the biodiversity exploratories. Basic Appl Ecol. 2010;11:473-85

26. Hessenmöller D, Nieschulze J, Von Lüpke N, Schulze ED. Identification of forest management types from ground-based and remotely sensed variables and the effects of forest management on forest structure and composition. Forstarchiv. 2011:82:171-83.

27. McGaughey RJ. FUSION/LDV: software for LiDAR data analysis and visualization. 2011.

28. Thurner M, Beer C, Santoro M, Carvalhais N, Wutzler T, Schepaschenko D, Shvidenko A, Kompter E, Ahrens B, Levick SR, Schmullius C. Carbon stock and density of northern boreal and temperate forests. Glob Ecol Biogeogr. 2014;23:297-310.

29. Thomas SC, Martin AR. Carbon content of tree tissues: a synthesis. Forests. 2012:3:332-52. 
30. Packalen P, Strunk JL, Pitkanen JA, Temesgen H, Maltamo M. Edge-tree correction for predicting forest inventory attributes using area-based approach with airborne laser scanning. Sel Top Appl Earth Obs Remote Sens IEEE J. 2015:8:1274-80.

31. Popescu SC. Estimating biomass of individual pine trees using airborne LiDAR. Multiple benefits from sustainable bioenergy systems. Proceedings of a joint workshop of IEA bioenergy Task 30 and Task 31, August 2005, Perth, Western Australia, IEA Bioenergy T31:2007:01 2007, 31:646-655.

32. Koch $B$, Heyder $U$, Weinacker $H$. Detection of individual tree crowns in airborne LiDAR data. Photogramm Eng Remote Sens. 2006;72:357-63.

33. Levick SR, Asner GP. The rate and spatial pattern of treefall in a savanna landscape. Biol Conserv. 2013:157:121-7.

34. Koukoulas S, Blackburn GA. Mapping individual tree location, height and species in broadleaved deciduous forest using airborne LiDAR and multispectral remotely sensed data. Int J Remote Sens. 2005;26:431-55.

35. Lu X, Guo Q, Li W, Flanagan J. A bottom-up approach to segment individual deciduous trees using leaf-off LiDAR point cloud data. ISPRS $J$ Photogramm Remote Sens. 2014;94:1-12.

36. Vauhkonen J, Ene L, Gupta S, Heinzel J, Holmgren J, Pitkanen J, Solberg S, Wang Y, Weinacker H, Hauglin KM, Lien V, Packalen P, Gobakken T, Koch B, Naesset E, Tokola T, Maltamo M. Comparative testing of single-tree detection algorithms under different types of forest. Forestry. 2012;85:27-40.

37. Shendryk I, Broich M, Tulbure MG, Alexandrov SV. Bottom-up delineation of individual trees from full-waveform airborne laser scans in a structurally complex eucalypt forest. Remote Sens Environ. 2016;173:69-83.
38. Böckmann T, Saborowski J, Dahm S, Nagel J, Spellmann H. Die Weiterentwicklung der Betriebsinventur in Niedersachsen. Forst Holz. 1998:53:219-226

39. McRoberts RE, Ståhl G, Vidal C, Lawrence M, Tomppo E, Schadauer K, Chirici G, Bastrup-Birk A. National forest inventories: prospects for harmonised international reporting. In: Tomppo E, Gschwantner T, Lawrence M, McRoberts RE, editors. National forest inventories. Dordrecht: Springer; 2010. p. 33-43.

40. Wulder MA, Coops NC, Hudak AT, Morsdorf F, Nelson R, Newnham G, Vastaranta M. Status and prospects for LiDAR remote sensing of forested ecosystems. Can J Remote Sens. 2014;39:S1-5.

41. Calders K, Newnham G, Burt A, Murphy S, Raumonen P, Herold M, Culvenor D, Avitabile V, Disney M, Armston J, Kaasalainen M. Nondestructive estimates of above-ground biomass using terrestrial laser scanning. Methods Ecol Evol. 2015;6:198-208.

42. Srinivasan S, Popescu S, Eriksson M, Sheridan R, Ku N-W. Terrestrial laser scanning as an effective tool to retrieve tree level height, crown width, and stem diameter. Remote Sens. 2015;7:1877-96.

43. Hackenberg J, Spiecker H, Calders K, Disney M, Raumonen P. SimpleTree-an efficient open source tool to build tree models from TLS clouds. Forests. 2015;6:4245-94.

44. Dubayah R, Goetz SJ, Blair JB, Fatoyinbo TE, Hansen M, Healey SP, Hofton MA, Hurtt GC, Kellner J, Luthcke SB, Swatantran A. The global ecosystem dynamics investigation. In: AGU fall meeting abstracts. Washington, D.C., United States: American Geophysical Unionvol. 1. 2014. p. 07.

\section{Submit your manuscript to a SpringerOpen ${ }^{\odot}$ journal and benefit from:}

- Convenient online submission

- Rigorous peer review

- Immediate publication on acceptance

- Open access: articles freely available online

- High visibility within the field

- Retaining the copyright to your article 